REVIEW

\title{
Management of traumatic brain injury: some current evidence and applications
}

A Guha

Postgrad Med J 2004;80:650-653. doi: 10.1136/pgmj.2004.019570

Traumatic brain injury remains a worldwide problem. Newer modalities in the management of such injuries include both drugs and therapeutic strategies. Continuing research in animal models has provided a better understanding of the pathophysiological processes that follow head injury, and this in turn has enabled workers to work on improved treatment targets. Although there are exciting and novel approaches emerging, there is no substitute for meticulous initial resuscitation. Additionally, some of the more well known management options are now better understood. These concepts are discussed in the article.

\section{Correspondence to: Dr Arpan Guha, Walton Centre for Neurology and Neurosurgery and University Hospital Aintree, Longmoor Lane, Liverpool L9 7AL, UK; arpan1@yahoo.com}

Submitted 24 January 2004 Accepted 24 March 2004
$\mathrm{T}$ he socioeconomic impact of moderate and severe head injury is quite severe. It has long been recognised as a leading cause of mortality and morbidity in adults of the western world, and traumatic brain injury (TBI) is said to directly contribute to nearly $30 \%$ of deaths in trauma. When we consider that trauma is largely a "disease" of the young, there is an obvious, major economic impact felt by a nation as a whole. It is also being recognised that even minor head injuries may lead to long term sequelae, further consuming scarce rehabilitation resources. Stroke and aneurysmal subarachnoid haemorrhage also contribute to acute brain injury. Many of the concepts that apply to the critical care management of TBI apply to brain protection in general.

Although some of the current work is novel and exciting, for example, the role of inflammatory mediators and neuroregeneration in the treatment of brain injury, there has also been an improvement in the understanding of the basic concepts that contribute to critical care management of these patients. Both these aspects will be discussed here in the context of treating TBI.

\section{OUTLINE OF PATHOPHYSIOLOGY}

The initial or primary injury produces neuronal death and damage. The primary injury may be simple haematomas or more complex and diffuse lesions. However, it then sets off a cascade of molecular events that lead to secondary injury. These include the effects of hypoxia, release of endogenous excitatory amino acids, production of proinflammatory substances and free radicals. These processes, if unchecked, produce more destruction (box 1, fig 1).

\section{DIFFICULTY WITH CLINICAL TRIALS}

Brain injury in humans is a heterogeneous disease with different pathological processes (box 1, fig 1). Most of the neuroprotective agents have been studied in experimental TBI models in animals. Although animal models provide most of our pathophysiological understanding of TBI, they are essentially induced, isolated head injuries. For instance, the popular fluid percussion model produces a predominantly focal injury, although in reality human TBI consists of a significant diffuse axonal injury as well. It is also being recognised that the response to a TBI is modified by a differential response determined by genetic predisposition. All these factors contribute to the difficulty in transferring what is effective in animal models to clinical therapy in humans.

However, currently, models examining specific secondary insults, that is hypoxia, hypercarbia, hypovolaemia and hypotension, associated with more complex research into endogenous excitatory and inflammation pathways, are providing us with more information.

\section{TARGETS FOR THERAPY}

Meticulous management of basic principles It has been long recognised that basic principles of resuscitation, carried out in the universal "airway, breathing, circulation" manner as advocated by trauma courses, are vital for a good outcome. No amount of sophisticated critical care treatment or "magic bullets" can be substituted for this initial management in arresting the effect of primary injury. This is the "platinum 10 minutes" and the "golden hour" of intervention.

This can be summarised as:

Airway maintenance, with cervical spine control: any head injured patient with a Glasgow coma score less than 8 should be intubated. A rapid sequence technique is recommended, and anaesthetic drugs (for example, thiopental or propofol for induction with suxamethonium for muscle relaxation) must be used to avoid fatal increases in intracranial pressure (ICP). ${ }^{1}$

Breathing, or ventilation must be optimised to "low normocapnia", that is arterial partial pressure of carbon dioxide $\left(\mathrm{PaCO}_{2}\right)$ of 4-4.5 kPa.

Abbreviations: CPP, cerebral perfusion pressure; EEG, electroencephalography; ICP, intracranial pressure; NABIS H (trials), National Acute Brain Injury Study: Hypothermia; NMDA, N-methyl-D-aspartate; $\mathrm{PaCO}_{2}$, arterial partial pressure of carbon dioxide; $\mathrm{P}(\mathrm{a}) \mathrm{O}_{2}$, (arterial) partial pressure of oxygen; TBI, traumatic brain injury 


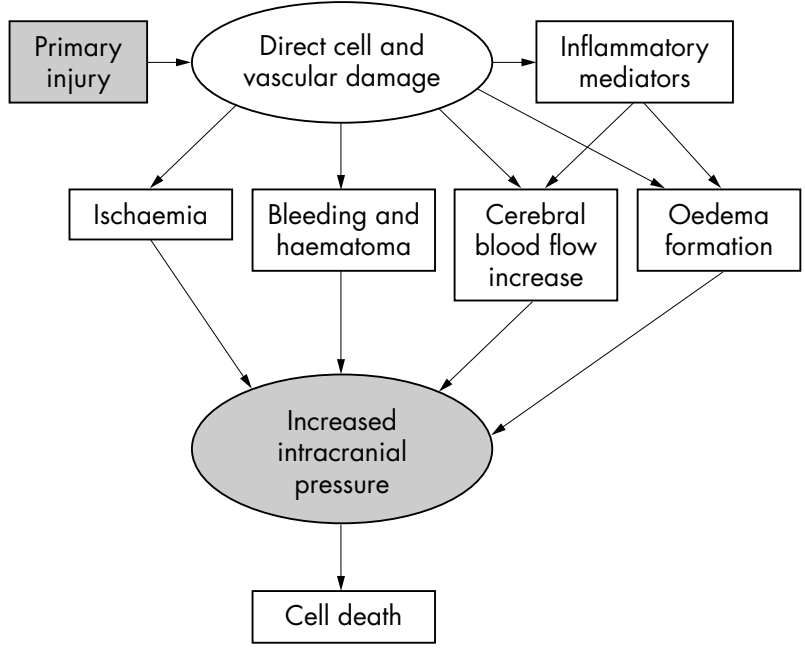

Figure 1 Processes in traumatic brain injury.

Hyperventilation to lower $\mathrm{PaCO}_{2}$ levels is associated with worse outcomes. ${ }^{2}$ An arterial partial pressure of oxygen $\left(\mathrm{PaO}_{2}\right)$ greater than $13 \mathrm{kPa}$ should be maintained. Until arterial blood gases can be measured, non-invasive monitoring with a pulse oximeter and capnograph is recommended. ${ }^{3}$

Circulation is maintained by fluids and inotropes to maintain a mean arterial blood pressure of $90 \mathrm{~mm} \mathrm{Hg} .{ }^{4}$ The primary aim in the resuscitation of a patient with brain injury with or without trauma is the maintenance of euvolaemia. Although the concept of "permissive hypotension" in haemorrhagic shock - that is, maintenance of a systolic blood pressure of around $80 \mathrm{~mm} \mathrm{Hg}$ is popular with some practitioners, it has no place if associated with a significant TBI.

After brain injury, and especially in the multiply injured patient, cerebral blood flow may be lowered to the ischaemic threshold. To prevent further neuronal death (secondary brain injury), the flow of well oxygenated blood must be restored. This means maintenance of a reasonable cerebral perfusion pressure (CPP). There is no class I evidence for the optimum level of CPP, but $70-80 \mathrm{~mm} \mathrm{Hg}$ is probably the critical threshold. Therefore, maintenance of a mean arterial pressure of $90 \mathrm{~mm} \mathrm{Hg}$ is usually recommended. ${ }^{5}$ Mortality increases approximately $20 \%$ for each $10 \mathrm{~mm} \mathrm{Hg}$ loss of CPP. In those studies where CPP is maintained above $70 \mathrm{~mm} \mathrm{Hg}$, the reduction in mortality is as much as $35 \%$ for those with severe head injury. ${ }^{6}$

\section{Promising strategies}

\section{Osmotherapy and fluid considerations}

Mannitol

Osmotherapy has been used since the first published use of mannitol to treat raised ICP. ${ }^{7}$ Mannitol remains the standard against which other ICP lowering fluids are compared.

The usual dose in which mannitol is recommended is 0.5$1 \mathrm{~g} / \mathrm{kg}$. However, some recent work has evaluated long term clinical outcomes and postoperative physiological findings in acutely comatose patients receiving early preoperative emergency room high dose mannitol $(1.4 \mathrm{mg} / \mathrm{kg})$ compared with conventional dose mannitol $(0.7 \mathrm{mg} / \mathrm{kg})$ treatment. ${ }^{8}$ Although this study was confined to non-missile surgical intraparenchymal temporal lobe haemorrhages with abnormal pupillary widening, the same authors then demonstrated improvement with comatose patients with acute subdural haematomas too. ${ }^{9}$ This may suggest using a higher dose of mannitol than previously recommended.
Box 1: Processes causing secondary brain injury

- Ischaemia, excitotoxicity, and energy failure.

- Neuronal death cascades.

- Cerebral swelling.

- Inflammation.

\section{Hypertonic saline}

Currently, the most researched area has been the use of hypertonic saline. This is an agent that is already being used therapeutically. Although its recent popularity was initiated by noticing its usefulness in the fluid resuscitation of penetrating trauma with haemorrhagic hypotension, it has become quite clear that it is effective in concentrations of $3 \%-7.5 \%$ in lowering ICP. ${ }^{10}$

Mirski and others showed in a rat model that although single, equiosmolar bolus doses of hypertonic saline and mannitol were effective in reducing raised ICP, hypertonic saline was significantly more effective $(53.9 \%$ reduction $v$ $35.0 \%) .{ }^{11}$ The therapeutic action of hypertonic saline was longer and lasted up to up to 500 minutes. With mannitol there was return and overshooting of the baseline raised ICP by $10 \%$ to $25 \%$ by 120 minutes after dosing. A hypertonic saline-dextran combination $\mathbf{( 7 . 2 \%}$ sodium chloride/10\% dextran 60) after experimental TBI in was also noted to completely prevent secondary diameter increase in cerebral blood vessels, and also the aggregation of white blood cells was reduced by $90 \% .{ }^{12}$ This would clearly improve the microcirculatory disturbances that follow TBI in small vessels in the brain.

Numerous human studies have since showed benefits with hypertonic saline. The most recent clinical work in humans studied patients who were randomly assigned to receive $2 \mathrm{ml} /$ $\mathrm{kg}$ of either $7.5 \%$ hypertonic saline solution or $20 \%$ mannitol. The mean number of intracranial hypertension episodes per day and the daily duration of intracranial hypertension episodes were significantly lower in the hypertonic saline solution group. The rate of clinical failure was also significantly lower in the hypertonic saline solution group. ${ }^{13}$

The theoretical concerns with hypertonic saline include the development of central pontine myelinolysis and rapid brain shrinkage leading to tearing of bridging vessels. However, pontine myelinolysis is seen if chronic hyponatraemia is rapidly corrected, and as this is usually not the case when ICP is being treated, this has not been reported in the literature during clinical use in humans. In the presence of normal renal function and TBI, the increased sodium load is usually corrected without any renal side effects.

Although further larger and more extensive studies are required, hypertonic saline not only seems to be a good alternative to mannitol in managing brain oedema and raised ICP, but may well offer several therapeutic advantages.

\section{Barbiturates}

High dose barbiturate therapy is usually reserved for refractory intracranial hypertension in patients who are felt to be salvageable. They exert a beneficial effect by lowering the cerebral metabolic rate for oxygen and modulating vascular tone. They also have additional effects such as membrane stabilisation and reducing lipid peroxidation. ${ }^{14}$ The most comprehensive review and meta-analysis by Roberts felt that there was no evidence that barbiturate therapy in patients with acute severe head injury improved outcome. ${ }^{15}$ Barbiturate therapy also resulted in a fall in blood pressure in one in four treated patients.

However, there is little doubt that it is widely used in the setting of difficult to control ICP. Clinical users will invariably 
notice increased requirements for inotropic support to maintain an adequate CPP due to the adverse effects of continuous infusions on the cardiovascular system. In our centre, thiopental sodium is used in an initial loading dose of $5-10 \mathrm{mg} / \mathrm{kg}$ followed by an infusion that is titrated using a cerebral function monitor to obtain burst suppression electroencephalography (EEG), which indicates maximum metabolic suppression. Indeed, the use of thiopental without a cerebral function monitor or equivalent EEG monitoring cannot be recommended as over-suppression of EEG is not beneficial and leads to increased risks of systemic complications. It is also important to remember that mechanisms other than, or at least in addition to, metabolic suppression may contribute to the protective effect of barbiturates, as a differential effect between thiopental, methohexital and pentobarbital has been described. ${ }^{16}$

Temperature control

Hypothermia has been shown to be neuroprotective in many TBI models. Several mechanisms for this have been postulated, including decreased excitatory amino acids in the injured area, ${ }^{17}$ augmenting antioxidant activity, ${ }^{18}$ and reducing inflammatory markers. ${ }^{19}$ So far, randomised controlled trials of mild hypothermia $\left(32-34^{\circ} \mathrm{C}\right)$ have provided conflicting results. Although Clifton et al were able to show a possible outcome benefit of mild hypothermia compared with normothermia in patients who had Glasgow coma scores of $5-7,{ }^{20}$ the large American, multicentre, NABIS HI (National Acute Brain Injury Study: Hypothermia) trial results failed to show any beneficial effect on outcome. ${ }^{21}$ However, this study has been criticised on several counts: intercentre variability in treatment, delay in reaching target, and inconsistent fluid therapy. As treatment benefit could be shown by subgroup analysis in patients who arrived at the study centre with a low body temperature $\left(\leqslant 35.0^{\circ} \mathrm{C}\right)$, and in whom hypothermia was maintained, a second multicentre study with tighter protocols is in progress (NABIS H2).

There is, however, little doubt that increased systemic and brain temperature is detrimental to outcome. ${ }^{22}$ Further work has demonstrated that brain tissue $\mathrm{Po}_{2}$ decreases with hypothermia, with a significant reduction below $35^{\circ} \mathrm{C}$, suggesting that decreasing brain temperature below $35^{\circ} \mathrm{C}$ may impair brain tissue oxygenation. ${ }^{23}$ Our clinical practice is to monitor core temperature regularly and prevent its rise by using antipyretic agents. Systemic infections contributing to pyrexia are identified and treated aggressively. In refractory cases, we use electrical cooling blankets to maintain moderate hypothermia $\left(35^{\circ} \mathrm{C}\right)$, as prevention of brain hyperthermia is probably more important that hypothermic treatment.

\section{Neuromuscular blockade}

Neuromuscular blockade is frequently used in mechanically ventilated head injured patients, especially to prevent coughing in the initial 24-48 hours of treatment in the intensive care unit. Although previously thought not to penetrate into the brain, it is now known that muscle relaxants do cross the blood-brain barrier, and could possibly activate brain acetylcholine receptors, leading to central autonomic dysfunction, weakness, and seizures. ${ }^{24}$ Furthermore, use should be monitored using a peripheral nerve stimulator, as resistance due to receptor up-regulation is often present. Certainly, consideration should be given to discontinuing muscle relaxant drugs when patients are adequately sedated.

\section{Newer drugs and strategies}

Although several drugs seemed promising as neuroprotective agents in animal models of TBI, none has so far shown to be effective in the human clinical setting. However, they do represent the quest for agents that might become useful in the future.

\section{Dexanabinol}

The activation of $N$-methyl-D-aspartate (NMDA) receptors in brain injury causing glutamate surges and cellular calcium ion influxes that ultimately lead to neuronal death led to interest in NMDA receptor antagonists. Dexanabinol is a cannabinoid and a non-competitive NMDA receptor antagonist. Initial studies were encouraging in stroke and TBI in limiting oedema formation and ischaemic damage..$^{25-27} \mathrm{~A}$ phase II human trial has been conducted recently which included TBI patients within six hours of injury. ${ }^{26}$ The aim of the study was to determine the safety of a single administration of escalating doses of dexanabinol, studied sequentially. It was not only shown to be safe, but the mean time during which ICP exceeded $25 \mathrm{~mm} \mathrm{Hg}$ and systolic blood pressure was less than $90 \mathrm{~mm} \mathrm{Hg}$ was decreased.

The difference with dexanabinol, compared to earlier disappointing trials with NMDA antagonists such as selfotel, is perhaps due to its unique ability to not only block NMDA receptors, but act additionally as an antioxidant and cytokine inhibitor. It is currently in phase III trials and seems the most promising of all the pharmacotherapeutic agents being studied.

\section{Anti-inflammatory agents}

Inflammatory responses mediated by cytokines contribute to secondary damage in TBI. This is now a major research focus. It is known that interleukin-l expression increases after brain injury. Investigators at University of Manchester are now studying the effects of interleukin-1 receptor antagonists as neuroprotective agents. This agent is already licenced in the treatment of rheumatoid arthritis, and its profile is well known.

Corticosteroids are potent anti-inflammatory agents, and beneficial effects have been recognised if administered early in trauma, especially using high dose methylprednisolone in spinal trauma. A systematic review of trials concluded that data were consistent with a $2 \%$ reduction in mortality. ${ }^{28}$ This has initiated the ongoing, multicentre CRASH trial (Corticosteroid Randomisation After Significant Head Injury) which is being coordinated from the UK. ${ }^{29}$ This trial had recruited over 5000 patients until the end of April 2003, and treatment consists of a $2 \mathrm{~g}$ loading dose of methylprednisolone, followed by an infusion of $0.4 \mathrm{~g} /$ hour for 48 hours.

\section{Lund therapy}

The Lund therapy is a completely different strategy in the management of brain injury. ${ }^{30}$ This is a Swedish strategy from Lund University Hospital, based on principles for brain volume regulation and improved microcirculation. Thus, it is quite different to the traditional CPP/ICP based treatment, and seems based on sound physiological principles. Interstitial fluid resorption is carried out by lowering intracapillary hydrostatic pressure, by preserving normal colloid osmotic pressure, and by maintaining a normovolaemic (normal albumin/serum and haemoglobin) patient. Intracapillary pressure is reduced using low dose thiopental and dihydroergotamine to cause precapillary vasoconstriction. Mean arterial pressure is reduced with metoprolol and clonidine to reduce oedema caused by increased hydrostatic pressure. Clonidine, in combination with normovolaemia, also improves microcirculation by reducing catecholamines in plasma. The reported results are excellent, but the control group was historical. A randomised, controlled, multicentre study is required before this novel way of treating TBI gains widespread acceptance. 


\section{CONCLUSION}

It is clear that there is a not only a worldwide interest in developing drugs that may modify and reduce secondary injuries in TBI, but also in the development of treatment strategies. As our understanding of pathophysiological pathways in TBI increases, so does our ability to try and limit the damage caused by these processes. Future researches will doubtless focus on neurotrophic and neurogenerative factors to try and repopulate damaged nerve cells. Some of the results of these studies are already being published. ${ }^{31}$ Further evaluation of pathological time courses will enable researches to initiate therapy at specific times. Clearly, in a heterogeneous and multifactorial process such as TBI, multifocal therapeutic strategies will probably have more success than single drugs. However, till such time, the meticulous attention to basic treatment principles by clinicians on the ground will continue to remain important.

\section{REFERENCES}

1 Guha A. Prehospital care of trauma must be improved in UK. BMJ 2001;323:1070.

2 Muizelaar JP, Marmarou A, Ward JD, et al. Adverse effects of prolonged hyperventilation in patients with severe head injury: a randomized clinical trial. J Neurosurg 1991;75:731-9.

3 Helm M, Schuster R, Hauke J, et al. Tight control of prehospital ventilation by capnography in major trauma victims. Br J Anaesth 2003;90:327-32.

4 Marmarou A, Anderson RL, Ward JD, et al. Impact of ICP instability and hypotension on outcome in patients with severe head trauma. J Neurosurg 1991;75:S59-66.

5 Rosner MJ, Daughton S. Cerebral perfusion pressure management in head injury. J Trauma 1990;30:933-41.

6 Chesnut RM, Marshall SB, Pick J, et al. Early and late systemic hypotension as a frequent and fundamental source of cerebral ischaemia following severe brain injury in the Traumatic Coma Data Bank. Acta Neurochir Suppl (Wien) 1993;59:121-5.

7 Wise BL, Chater N. The value of hypertonic mannitol solution in decreasing brain mass and lowering cerebrospinal fluid pressure. J Neurosurg 1962;19:1038-43.

8 Cruz J, Minoja G, Okuchi K. Major clinical and physiological benefits of early high doses of mannitol for intraparenchymal temporal lobe hemorrhages with abnormal pupillary widening: a randomized trial. Neurosurgery 2002:51:628-37, discussion 637-8

9 Cruz J, Minoja G, Okuchi K. Improving clinical outcomes from acute subdural hematomas with the emergency preoperative administration of high doses of mannitol: a randomized trial. Neurosurgery 2001;49:864-71.

10 Zornow MH. Hypertonic saline as a safe and efficacious treatment of intracranial hypertension. J Neurosurg Anesthesiol 1996;8:175-7.

11 Mirski AM, Denchev ID, Schnitzer SM, et al. Comparison between hypertonic saline and mannitol in the reduction of elevated intracranial pressure in a rodent model of acute cerebral injury. J Neurosurg Anesthesiol 2000; 12:334-44.
12 Hartl R, Medary MB, Ruge M, et al. Hypertonic/hyperoncotic saline attenuates microcirculatory disturbances after traumatic brain injury. Trauma 1997; 42(5 suppl):S41-7.

13 Piatt JH, Schiff SJ. High dose barbiturate therapy in neurosurgery and intensive care. Neurosurgery 1984;15:427-44.

14 Vialet R, Albanese J, Thomachot L, et al. Isovolume hypertonic solutes (sodium chloride or mannitol) in the treatment of refractory posttraumatic intracranial hypertension: $2 \mathrm{ml} / \mathrm{kg} 7.5 \%$ saline is more effective than $2 \mathrm{ml} / \mathrm{kg} 20 \%$ mannitol. Crit Care Med 2003:31:1683-7.

15 Roberts I. Barbiturates for acute traumatic brain injury (Cochrane Review). The Cochrane Library. Issue 2. Oxford: Update Software, 2003.

16 Cole DJ, Cross LM, Drummond JC, et al. Thiopentone and methohexital, but not pentobarbitone, reduce early focal cerebral ischaemic injury in rats. Can J Anaesth 2001;48:807-14.

17 Globus MY, Alonso O, Dietrich WD, et al. Glutamate release and free radical production following brain injury: effects of post-traumatic hypothermia. J Neurochem 1995;65:1704-11.

18 Karibe H, Chen SF, Zarow GJ, et al. Mild intraischemic hypothermia suppresses consumption of endogenous antioxidants after temporary focal ischemia in rats. Brain Res 1994;649:12-18.

19 Aibiki M, Maekawa S, Ogura S, et al. Effect of moderate hypothermia on systemic and internal jugular plasma IL6 levels after traumatic brain injury in humans. J Neurotrauma 1999;16:225-32.

20 Clifton GL, Miller ER, Choi SC, et al. Lack of effect of induction of hypothermia after acute brain injury. N Engl J Med 2001;344:556-63

21 Grocott HP, Mackensen GB, Grigore AM, et al. Postoperative hyperthermia is associated with cognitive dysfunction after coronary artery bypass graft surgery. Stroke 2002;33:537-41

22 Gupta AK, Al-Rawi PG, Hutchinson PJ, et al. Effect of hypothermia on brain tissue oxygenation in patients with severe head injury. $\mathrm{Br} J$ Anaesth 2002;88:188-92.

23 Murray MJ, Cowen J, DeBlock H, et al. Clinical practice guidelines for sustained neuromuscular blockade in the critically ill adult patient. Crit Care Med 2002;30:142-56.

24 Shohami E, Gallily R, Mechoulam R, et al. Cytokine production in the brain following closed head injury: dexanabinol (HU-211) is a novel TNF-a inhibitor and an effective neuroprotectant. J Neuroimmunol 1997;72:169-77.

25 Belayev L, Busto R, Zhao W, et al. HU-211, a novel non-competitive NMDA antagonist, improves neurological deficit and reduces infarct volume after reversible focal cerebral ischemia in the rat. Stroke 1995;26:2313-20.

26 Biegon A, Belayev L, Bendel P, et al. MRI study of rat brain edema after head trauma: effects of HU-211, a nonpsychotropic cannabinoid. Am Soc Neurosci Abst 1993; 19:1485.

27 Knoller N, Levi L, Shoshan I, et al. Dexanabinol (HU-211) in the treatment of severe closed head injury: a randomized, placebo-controlled, phase II clinical trial. Crit Care Med 2002;30:548-54.

28 Alderson P, Roberts I. Corticosteroids in acute traumatic brain injury: a systematic review of randomised trials. BMJ 1997;314:1855-9.

29 London School of Hygiene and Tropical Medicine. Corticosteroid randomisation after significant head injury. Available at: http:// www.crash.Ishtm.ac.uk.

30 Eker C, Asgeirsson B, Grande PO, et al. Improved outcome after severe head injury with a new therapy based on principles for brain volume regulation and preserved microcirculation. Crit Care Med 1998;26:1881-6.

31 Dietrich WD, Alonso O, Busto R, et al. Posttreatment with intravenous basic fibroblast growth factor reduces histological damage following fluid percussion brain injury in rats. J Neurotrauma 1996;13:309-16. 